Atıf için / For Citation: S. Uzun, Z. Demircioğlu, "Bis[2-(metilamino)troponato]bakır(II) Molekülünün Yapısal ve Elektronik Özelliklerinin Deneysel ve Kuramsal Analizleri”, Süleyman Demirel Üniversitesi Fen Edebiyat Fakültesi Fen Dergisi, 15(1), 9-22, 2020.

\title{
Bis[2-(metilamino)troponato]bakır(II) Molekülünün Yapısal ve Elektronik Özelliklerinin Deneysel ve Kuramsal Analizleri
}

\author{
Serap UZUN ${ }^{1 *}$, Zeynep DEMIRCIOĞLU ${ }^{2}$ \\ ${ }^{1}$ Samsun Üniversitesi, Mühendislik Fakültesi, Temel Bilimler Bölümü, 55420, Samsun, Türkiye \\ ${ }^{2}$ Sinop Üniversitesi, Fen Edebiyat Fakültesi, Fizik Bölümü, 57000, Sinop, Türkiye \\ *yazışllan yazar e-posta: serap.uzun@ samsun.edu.tr
}

(Alinış / Received: 19.09.2019, Kabul / Accepted: 03.01.2020, Yayımlanma / Published: 31.05.2020)

Özet: Bis[2-(metilamino)troponato]bakır(II) molekülünün moleküler, elektronik ve kimyasal yapısı incelendi. Hesaplamalı kimya yöntemlerinden yoğunluk fonksiyonel kuramı kullanılarak molekülün deneysel olarak elde edilemeyen lokal ve global kimyasal aktivite parametreleri ve elektrofilik ve nükleofilik doğasının belirlenmesi amaçlandı. Bunun yanı sıra çalışılan molelükün optik bir materyal olma eğilimi incelenmiştir. Yapının kararlılık enerjisi, konjüge etkileşimler, yörünge orbitallerinin stabilizasyonu, hibritleşme yüzdeleri ve geçiş durumları incelendi.

Anahtar kelimeler YFK, Kimyasal aktivite, Lineer olmayan optik özellikler

\section{Experimental and Theoretical Analysis of Structural and Electronic Properties of Bis [2- (methylamino) troponato]copper (II) Molecule}

\begin{abstract}
The molecular, electronic and chemical structure of the Bis[2(methylamino)troponato]copper(II) molecule was clarified. It is aimed to determine the local and global chemical activity parameters and electrophilic and nucleophilic nature by computational chemistry method of density functional theory of the molecule which can not be obtained experimentally. In addition, the tendency of the studied molecule to be an optical material has been investigated. Stabilization energy of the structure, conjugate interactions, stabilization of orbital orbitals, hybridization percentages and transition states were examined by natutal bond orbital analysis.
\end{abstract}

Key words: DFT, Chemical Activity, Nonliear Optical Properties

\section{Giriş}

Son yıllarda birinci ve ikinci geçiş elementlerini içeren tropolonato komplekslerine ilgi oldukça artmıştır. Bunun sebebi katalizör öncülerinde, tıp alanında ve ilaç endüstrisinde uygulama alanının yaygınlığıdır [1]. $\mathrm{Bu}$ çalışmada $\mathrm{Cu}$ (II) içeren tropolonato kompleksinin seçilme nedeni ilaç endüstrisi, tıp ve kimya gibi birçok alanda önemli derecede kullanılanılabilen etkin bileşikler [2-6] olmasıdır. Deneysel çalışmaları desteklemek veya deneysel çalışmalar yapmadan ulaşılabilecek özellikle kimyasal aktivite sonuçlarını önceden tahmin edebilmek amacıyla bilgisayar destekli kuantum kimyasal hesaplamalar, kuramsal moleküler modelleme programları kullanılarak yapılabilmektedir. Bu tür hesaplamaların temelini kuantum mekaniği oluşturmaktadır. Prensip olarak, kuantum teorisi ile bir molekülün bütün kimyasal özellikleri hesaplanabilir. Bilindiği üzere bir bileşiğin yapısı ve kimyası denel yöntemlerle 
belirlenebilir, ancak hesaplama yolu ile öngörünün yapılabilmesi çok yararlıdır ve pek çok uygulama alanı bulmuştur. Örneğin farmakolojide yeni ilaçların geliştirilmesinde yaygın olarak kullanılmaktadır. Fizikçiler ve kimyacılar bilgisayar kullanarak sentezden önce ilaçların yapıları hakkında önbilgiye sahip olurlar, ilaçta istenen özellikleri belirlerler, sonra bu özelliklere uygun sentezleri gerçekleştirirler böylelikle para ve zaman kaybını önlenmektedir. Bunların 1şığında incelenen Bis[2(metilamino)troponato]bakır(II) molekülüne ait literatürde mevcut olmayan kuramsal kimyasal aktivite çalışması yapılmıştır. İncelenen molekül grubuna benzer yapıların deneysel olarak sentezi ve X-ışını kırınımı deneyine ait çalışmaları literatürde mevcuttur [2-6].

$\mathrm{Bu}$ çalışmada molekülün kimyasal ve moleküler özelliklerinin kuramsal olarak incelenerek deneysel olarak elde edilemeyen sertlik ve yumuşaklık parametreleri, elektrofilik ve nükleofilik doğasının belirlenerek sonraki çalışmalara yol göstermesi hedeflenmektedir. Bis[2-(metilamino)troponato]bakır(II) kristalinin X-1şını kırınımı yöntemiyle geometrik parametrelerinin, hidrojen bağlarının ve moleküler yapısının aydınlatılması Steyl ve arkadaşları tarafından çalışılmıştır [1]. Çalışılan molekülün tüm kuramsal hesaplamaları, deneysel sonuçlara yakın, anlamlı değerler vermesi ve hesapsal maliyeti kısmen düşük olması nedeniyle YFK/B3LYP/6-31++G(d,p) kullanılarak elde edilmiştir. Moleküler elektrostatik potansiyel (MEP) haritası, Fukui fonksiyonları, net yükleri lokal kimyasal aktivite tayinini yaparken; sertlik ve yumuşaklık parametreleri ise global kimyasal aktivitenin belirlenmesinde kullanılan yöntemleri temsil etmektedir. Bunların yanı sıra lineer olmayan optik özellikler (NLO) hiperkutuplanabilirlik ( $\beta$ ) ve kutuplanabilirlik $(\alpha)$ parametleri ile belirlenerek optik materyal olma eğilimi incelenmiştir. Doğal bağ orbital analizinde orbital geçiş durumları, kararlılık enerjileri, hibritleşme yüzdeleri, toplam Lewis ve toplam Lewis olmayan etkileşim yüzdeleri hesaplanmıştır. Bunlara ek olarak Hirshfeld yüzey analizi ile yüzey haritaları olan $\mathrm{d}_{\text {norm, }}$ $\mathrm{d}_{\mathrm{i}}, \mathrm{d}_{\mathrm{e}}$, şekil indeksi ve eğrilik indeksi oluşturulmuş ve atomların birbiri ile olan \% etkileşimleri 2-boyutlu parmak izi bölgesi tayin edilmiştir. $\mathrm{Bu}$ çalışmada elde edilen sonuçlar; gelecek çalışmalar için bizlere yol gösterici olacağını düşünmekteyiz. Bu sonuçlar kullanılarak; geçiş elementleri içeren metal organik yapıların fiziksel özelliklerinin incelenmesinde yardımcı olacağını umut ediyoruz.

\section{Materyal ve Metot}

Bis[2-(metilamino)troponato]bakır(II) molekülünün kuramsal yapısını incelemek için üç boyutlu yaklaşık geometrisi GaussView [7] programında çizilerek Gaussian09 paket programında [8] giriş verisi olarak kullanılarak gaz fazında ve taban durumunda optimize edilmiştir. Tüm kuramsal hesaplamalarda yoğunluk fonksiyonel yöntemi ile Becke tipi 3parametreli Lee-Yang-Par modeli (B3LYP) ve 6-31++G(d,p) baz seti kullanılmıştır. İlk olarak taban durumunda çalışılan molekülün optimizasyonu yapılmıştır. Optimizasyon sonucunda elde edilen geometrik parametreler olan bağ uzunluğu, bağ açısı ve burulma açısının X-1şınları kırınımı deneyinden elde edilen parametreleri başarılı bir şekilde temsil ettiği bulunmuş ve seçilen yöntem ile baz setinin çalışılan molekül için oldukça başarılı olduğu öngörülmüştür. Optimizasyondan sonra öncü moleküler orbitaller olan HOMO ve LUMO enerjileri, global sertlik ve yumuşaklık parametreleri, lineer olmayan optik özellikleri (polarizebilite ve hiperpolarizebilite), net yükler (Mulliken ve doğal popülasyon yükleri), moleküler elektrostatik potansiyel haritası, Fukui fonksiyonları ile elektrofik ve nükleofilik bölgeleri belirlenmiştir ve bu başlıklar altında sonuçlar değerlendirilmiştir. Bunun yanı sıra Hirshfeld yüzey analizi ile elde edilen $d_{n o r m}, d_{i}, d_{e}$ 
haritalarının görsel olarak gösterimi, atomların \% etkileşimleri ve 2-boyutlu parmak izi tayini Crystal Explorer 3.1 [9] programı kullanılarak elde edilmiştir.

\section{Bulgular}

\subsection{Optimize Yapı}

Şekil 1a'da görüldügü üzere Bis[2-(metilamino)troponato]bakır(II) molekülünde $\left.[\mathrm{Cu} \text { (TropNMe) })_{2}\right] \mathrm{Cu}$ (II) iyonu iki TropNMe ligandı ile kare düzlemsel bir geometriye sahiptir. Moleküle ait X-ışını kırınımı deneyinden elde edilen görünüm Şekil 1a' de verilmiştir [1]. Cu-O1 ve Cu-O2 bağ uzunluğu X-1şınları kırınımı deneyinde 1,9313 (2) $\AA$ ve 1,9386 (2) $\AA$, kuramsal olarak ise sirasiyla $1,9501 \AA$ ve $1,9502 \AA$ olarak elde edilmiştir. $\mathrm{Cu}-\mathrm{N} 1$ ve $\mathrm{Cu}-\mathrm{N} 2$ bağ uzunlukları ise deneysel olarak 1.9276 (2) $\AA$ ve 1,9291 (2) $\AA$, kuramsal olarak da $1,9538 \AA$ ve $1,9539 \AA$ değerlerinde bulunmuştur. O1-Cu-N1 ve O2-Cu-N2 açıları deneysel olarak $82,292(4)^{\circ}$ ve $82,090(4)^{\circ}$ olarak literatürde verilmişken, bu açılar kuramsal olarak ise $81,709^{\circ}$ ve $81,7086^{\circ}$ olarak hesaplanmıştır. Çalışılan moleküle ait bağ uzunluğu ve bağ açısı değerleri literatür ile uyum içindedir [10-12]. Bis[2-(metilamino)troponato]bakır(II) molekülüne ait optimize yap1 görünümleri Şekil 1b'de verilmiştir.

Tablo 1'de X-1şını kırınımı deneyinden ve YFK/B3LYP/6-31++G(d,p)'den elde edilen geometrik parametreler karşılaştırmalı olarak verilmiştir. Beklendiği üzere deneysel ve kuramsal sonuçlarda gözlenen ufak farklılıklar kuramsal hesaplamaların yapıyı yalıtılmış, gaz fazındaki ortamda ve hiçbir etkileşimi dikkate almayan bir formda hesaplamasından kaynaklanmaktadır. Yoğunluk fonksiyonel kuramından elde edilen geometrik parametrelerin $\mathrm{X}$-ışınları verilerini başarılı bir şekilde temsil etmesinden dolayı seçtiğimiz yöntem ve baz setinin çalışılan molekül için oldukça başarılı bir seçim olduğu öngörülmüş̧ür.
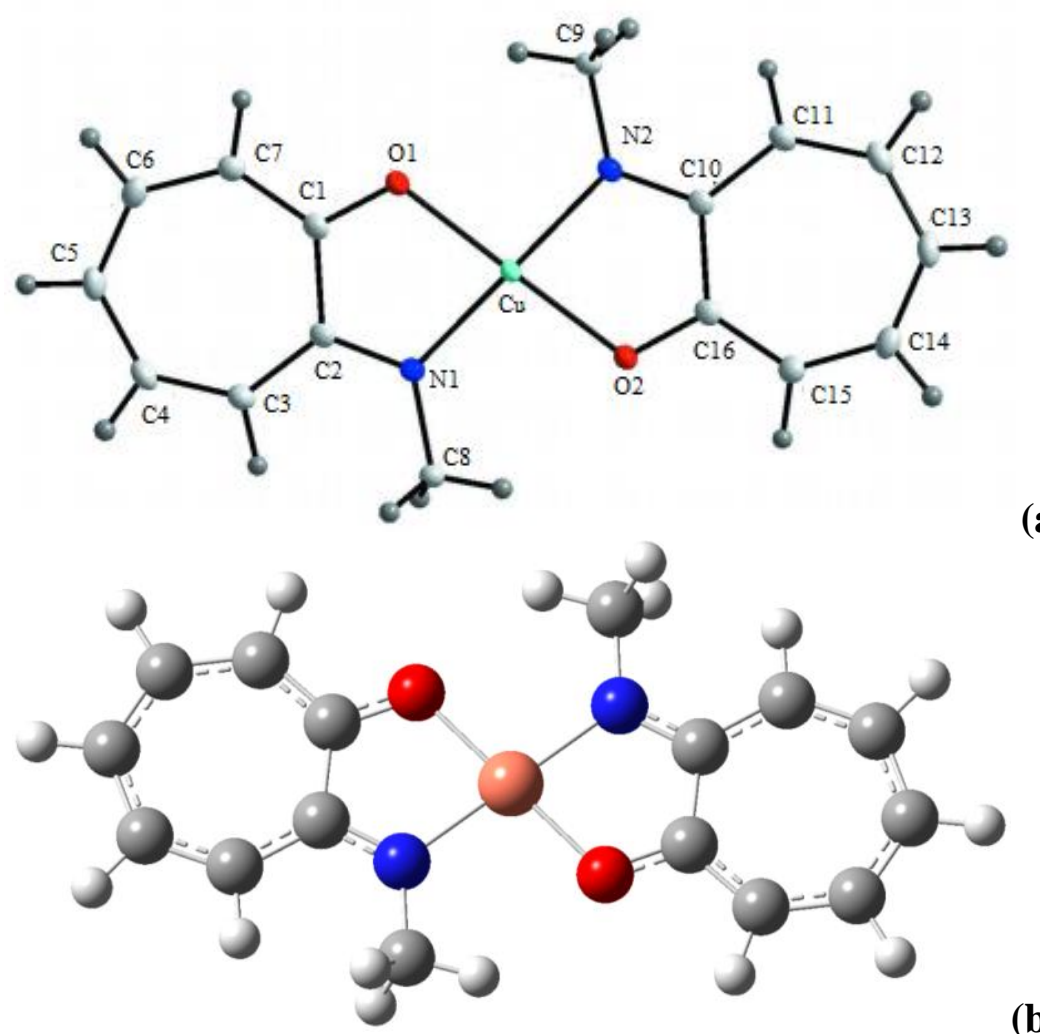

(a)

(b)

Şekil 1. a) Bis[2-(metilamino)troponato]bakır(II) molekülüne ait X-ışını kırınımı deneyinden elde edilen [1] ve b) optimize yapı görünümü 
Tablo 1. Çalışılan moleküle ait deneysel ve kuramsal geometrik parametre verileri

\begin{tabular}{ccc}
\hline $\begin{array}{c}\text { Bağ Uzunluğu }(\AA), \text { Bağ açısı }\left(^{\circ}\right) \\
\left.\text { ve Torsiyon açısı( }{ }^{\circ}\right)\end{array}$ & $\begin{array}{c}\text { X-işını Kırınımı } \\
\text { Deneyi } \mathbf{1}^{1]}\end{array}$ & YFK/B3LYP/6-31++G(d,p) \\
\hline $\mathrm{Cu}-\mathrm{O} 1$ & $1,9313(2)$ & 1,9501 \\
$\mathrm{Cu}-\mathrm{O} 2$ & $1,9386(2)$ & 1,9502 \\
$\mathrm{Cu}-\mathrm{N} 1$ & $1,9276(2)$ & 1,9538 \\
$\mathrm{Cu}-\mathrm{N} 2$ & $1,9291(2)$ & 1,9539 \\
$\mathrm{C} 1-\mathrm{O} 1$ & $1,2970(18)$ & 1,293 \\
$\mathrm{C} 2-\mathrm{N} 1$ & $1,3210(19)$ & 1,3296 \\
$\mathrm{C} 10-\mathrm{N} 2$ & $1,3196(19)$ & 1,3296 \\
$\mathrm{C} 16-\mathrm{O} 2$ & $1,2958(18)$ & 1,293 \\
$\mathrm{~N} 1-\mathrm{C} 8$ & $1,4551(18)$ & 1,4541 \\
$\mathrm{~N} 2-\mathrm{C} 9$ & $1,4582(18)$ & 1,4541 \\
$\mathrm{O} 1-\mathrm{Cu}-\mathrm{O} 2$ & $179,23(4)$ & 179,98 \\
$\mathrm{~N} 1-\mathrm{Cu}-\mathrm{N} 2$ & $175,77(5)$ & 179,9994 \\
$\mathrm{C} 1-\mathrm{O} 1-\mathrm{Cu}$ & $114,43(9)$ & 115,0025 \\
$\mathrm{C} 2-\mathrm{N} 1-\mathrm{Cu}$ & $115,20(10)$ & 115,1972 \\
$\mathrm{C} 10-\mathrm{N} 2-\mathrm{Cu}$ & $115,52(10)$ & 115,1975 \\
$\mathrm{C} 16-\mathrm{O} 2-\mathrm{Cu}$ & $114,48(9)$ & 115,0027 \\
$\mathrm{C} 2-\mathrm{N} 1-\mathrm{C} 8$ & $120,21(12)$ & 121,1996 \\
$\mathrm{Cu}-\mathrm{N} 2-\mathrm{C} 9$ & $124,15(10)$ & 125,5152 \\
$\mathrm{~N} 2-\mathrm{Cu}-\mathrm{O} 1-\mathrm{C} 1$ & $171,68(10)$ & $-179,9412$ \\
$\mathrm{~N} 1-\mathrm{Cu}-\mathrm{O} 1-\mathrm{C} 1$ & $-4,09(10)$ & 0,0593 \\
$\mathrm{~N} 2-\mathrm{Cu}-\mathrm{O} 2-\mathrm{C} 16$ & $5,04(10)$ & 0,0179 \\
$\mathrm{~N} 1-\mathrm{Cu}-\mathrm{O} 2-\mathrm{C} 16$ & $-179,20(10)$ & $-179,9827$ \\
$\mathrm{C} 2-\mathrm{N} 1-\mathrm{Cu}-\mathrm{O} 2$ & $-175,85(10)$ & 179,9197 \\
\hline & &
\end{tabular}

3.2. Global Kimyasal Aktivite: Öncü Moleküler Orbitaller ve Sertlik \& Yumuşaklık Parametreleri

En yüksek dolu moleküler orbital enerjisi (Еномо) ve en düşük boş moleküler orbital enerjisi ( $\mathrm{E}_{\text {LUMO }}$ ) öncü moleküler orbitaller olarak adlandırılmakta ve kimyasal reaksiyonlara katılan temel orbitaller olarak adlandırılmaktadır. HOMO enerjisi molekülün elektron verme, LUMO enerjisi ise molekülün elektron alma yeteneği olarak tanımlanır. Global kimyasal aktivite hesaplamalarında molekülün sertlikve yumuşaklık parametreleri HOMO ve LUMO orbital enerjileri ile hesaplanmaktadır [13]. Bu hesaplamalar optimize yapıyı gaz fazı ortamında gerçekleştirmektedir. Molekülden bir elektronu uzaklaştırmak için gerekli olan minimum enerji olan iyonizasyon enerjisi I = -

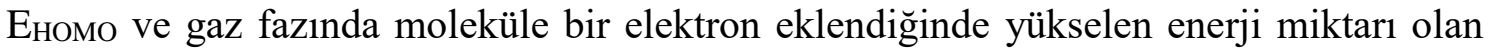

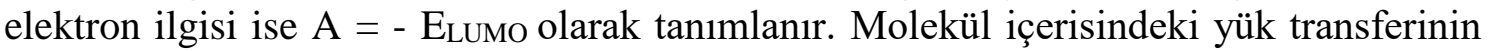
engellenmesinin bir ölçüsü olan sertlik değeri ise $\eta=(I-A) / 2$ ile verilir. Sertliğin tersi yumuşaklık parametresi ise $S=1 / 2 \eta$ ile temsil edilmektedir. Kimyasal sertliği yüksek olan moleküllerin molekül içi yük transferi azdır veya hiç gerçekleşmemektedir. Sertlik ve yumuşaklık parametrelerine ek olarak moleküldeki bir atomun elektronları çekme gücünü ifade eden $\chi=(\mathrm{I}+\mathrm{A}) / 2$ ise Mulliken elektronegatiflik parametresidir. Bunlara ek olarak elektrofilik indeks $w=\mu^{2} / 2 \eta$, kimyasal potansiyel $\mu=-(\mathrm{I}+\mathrm{A}) / 2$ ve maksimum yük transfer parametresi ise $\Delta N_{\max }=(\mathrm{I}+\mathrm{A}) / 2(\mathrm{I}-\mathrm{A})$ ile hesaplamıştır. 
Tablo 2. Çalışılan moleküle ait global kimyasal aktivite değerleri

\begin{tabular}{ccc}
\hline YFK/B3LYP/6-31++G(d,p) & $\boldsymbol{\alpha}$ & $\boldsymbol{\beta}$ \\
\hline EHOMO $\left._{\text {eV }}\right)$ & $-5,379$ & $-5,307$ \\
ELUMO $_{\text {LeV) }}$ & $-1,766$ & $-2,211$ \\
İyonizasyon enerjisi $(\mathrm{I})(\mathrm{eV})$ & 5,379 & 5,307 \\
Elektron ilgisi $(\mathrm{A})(\mathrm{eV})$ & 1,766 & 2,211 \\
Enerji aralığ $(\Delta \mathrm{E})(\mathrm{eV})$ & 3,612 & 3,096 \\
Elektronegatiflik $(\chi)(\mathrm{eV})$ & 3,572 & 3,759 \\
Kimyasal potansiyel $(\mu)(\mathrm{eV})$ & $-3,572$ & $-3,759$ \\
Kimyasal sertlik $(\eta)(\mathrm{eV})$ & 1,806 & 1,548 \\
Kimyasal yumuşaklik $(\mathrm{S})(\mathrm{eV})^{-1}$ & 0,276 & 0,322 \\
Elektrofilik indeks $(\mathrm{w})(\mathrm{eV})$ & 3,532 & 4,563 \\
Maksimum yük transfer parametresi $\Delta N_{\max }$ & 0,98 & 1,214 \\
\hline
\end{tabular}

Çalışılan moleküle ait $\alpha$ spini için $\mathrm{E}_{\mathrm{HOMO}}=-5,379 \mathrm{eV}, \mathrm{E}_{\mathrm{LUMO}}=-1,766 \mathrm{eV}$ ve $\Delta \mathrm{E}=3,612$ $\mathrm{eV}, \beta$ spini için bu değerler $\mathrm{E}_{\mathrm{HOMO}}=-5,307 \mathrm{eV}, \mathrm{E}_{\mathrm{LUMO}}=-1,766 \mathrm{eV}$ ve $\Delta \mathrm{E}=3,096 \mathrm{eV}$ olarak bulunmuştur. Molekülün $\alpha$ spinine ait sertlik değeri $1,806 \mathrm{eV}$, yumuşaklık parametresi $0,276 \mathrm{eV}$ iken $\beta$ spinin ait sertlik ve yumuşaklık parametreleri sırasılya 1,548 ve $0,322 \mathrm{eV}$ olarak hesaplanmıştır.

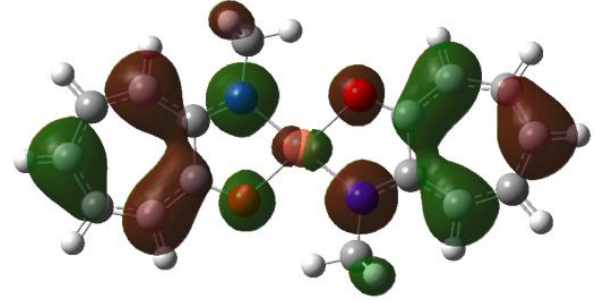

Еномо

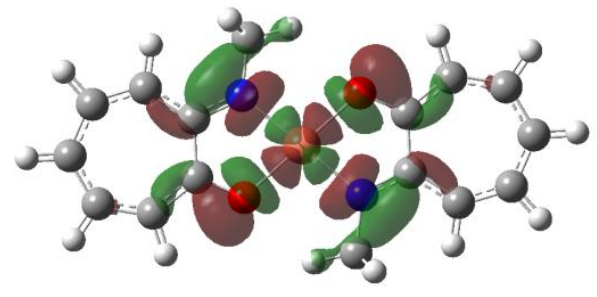

$\mathrm{E}_{\text {LUMO }}$

Şekil 2. Çalış1lan molekülün HOMO ve LUMO yüzey görünümleri

Diğer global kimyasal aktivite parametreleri Tablo 2'de ve HOMO ve LUMO yüzey görünümleri Şekil 2'de verilmiştir. Bu verilere göre göre düşük enerji aralığı, düşük sertlik ve yüksek yumuşaklık parametresine sahip olması çalışılan molekülün yüksek kimyasal aktivite ve düşük kinetik stabilite ile kimyasal aktiviteye yatkın olduğunu göstermektedir. Toprak ve arkadaşları tarafından yapılan bir çalışmada $\mathrm{Cu}$ (II) komplesine ait $\alpha$ spini için enerji aralığ $\Delta \mathrm{E}=3,526 \mathrm{eV}, \beta$ spini için bu $\Delta \mathrm{E}=2,818 \mathrm{eV}$ olarak elde edilmiş ve incelenen optimize yapının daha kararlı olduğu öngörülmüştür [14]. Enerji aralığ $10,10691 \mathrm{eV}$ olarak bulunan başka bir $\mathrm{Cu}(\mathrm{II})$ kompleksine göre ise Bis[2(metilamino)troponato]bakır(II) optimize yapısının oldukça yüksek sertlik ve düşük yumuşaklığa sahip olduğu söylenebilir [15].

\subsection{Lokal Kimyasal Aktivite: Moleküler Elektrostatik Potansiyel (MEP)}

Moleküler elektrostatik polansiyel (MEP) elektrofilik ve nükleofilik dağanın belirlenmesinde, moleküler davranışlarının reaktifliği, yapı aktifliği ve hidrojen bağlarının açıklanmasında sıklıkla kullanılan bir yöntemdir. Elektrostatik potansiyel yüzeyinin farklı değerleri farklı renklerin atanmasıyla yorumlanır [16]. Potansiyel artışı kırmızı $<$ turuncu $<$ sarı $<$ yeşil $<$ mavi olarak tanımlanır. MEP haritasında nötral molekülde elektronca fakir bölge mavi ile kodlanırken elektronca zengin bölgeler ise kırmızı renkli gözükmektedir. En negatif bölgeler kırmızı ile kodlanmış olarak görülmektedir ve oksijen atomları üzerinde yerelleşmiştir. Bu bölgeler hidrojen bağlarının oluşumunda aktif olan ve elektrofilik yatkınlığ 1 fazla olan bölgeleri temsil etmektedir. En pozitif nükleofilik 
doğanın baskın olduğu bölgeler ise metil ve hidrojen atomlarının yoğun olduğu bölgelerde yerelleşmiş konumda bulunmaktadır. Azot atomlarının elektronegatifliği ise komşu $\mathrm{Cu}$ atomu ve hidrojen atomlarının varlığı ile perdelenerek sarıya kayma göstermiştir. MEP yüzeyi Şekil 3a'da MEP kontör yüzeyi ise Şekil 3b'de verilmiştir. MEP kontör yüzeyinde ise elektron yoğunluğunun iki boyutlu yüzey eğrileri şeklinde verilmiş gösterimi mevcuttur.

Yapıların kimyasal aktiviteye yatkın olması, molekül içi ve moleküller arası hidrojen bağlarının varlığı yapıların elektrofilik doğasının daha baskın olduğunu öngörmektedir.

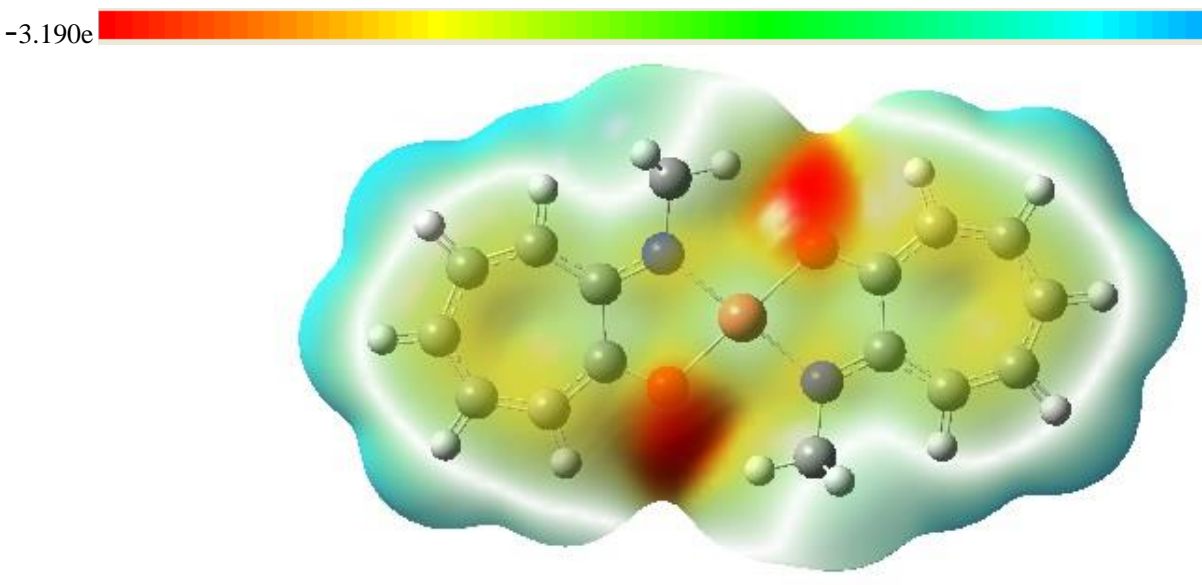

a) MEP

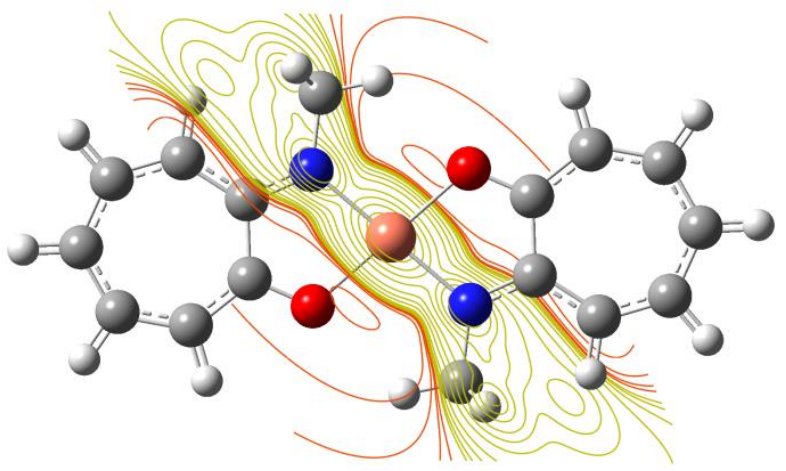

b) MEP kontör

Şekil 3. Çalışılan moleküle ait MEP görünümü

\subsection{Lokal Kimyasal Aktivite: Mulliken ve Doğal Populasyon Yükleri (MP \& NP)}

Mulliken populasyon analizi net yüklerin belirlenmesinde en eski ve en yaygın kullanılan yöntemlerin başında gelmektedir. Bu method atomik orbitallerin doğrusal kombinasyonu ile moleküler orbitallerin elde edilmesi ve dalga fonksiyonlarının atomlara dağılımında iki orbitalin çakıştığı durumlarda eşit dağılım ilkesine dayanmaktadır. Ancak bu eşit dağılım bir atomun daha elektronegatif olduğu durumlarda tam doğru sonuç vermez [17]. Bunu daha doğruya yakınsatmak için güçlü bazsetleri kullanmak elverişli bir durumdur. Bu sebeple Mulliken yükleri deneysel sonuçları nicel olarak tahmin etmek yerine nitel bir takım tahminler yapmak için kullanılmasının uygun olduğu öngörülmüştür. Doğal popuslasyon yük analizi de Mulliken'e benzer kuramsal bir hesaplama yöntemidir. Doğal bağ orbital analizi sonucunda net yüklerin bulunmasını sağlamaktadır. Her iki yöntemde elde edilen net yük değerleri birbiri ile oldukça iyi bir uyuma sahiptir. Tablo 3'de MP ve 
NP net yüklerine ait değerler verilmiştir. Beklendiği üzere, MP verilerine göre en negatif yükler $\mathrm{O} 1>\mathrm{O} 2>\mathrm{C} 12>\mathrm{C} 4>\mathrm{N} 2>\mathrm{C} 8>\mathrm{N} 1>\mathrm{C} 9>\mathrm{C} 14>\mathrm{C} 6>\mathrm{C} 5>\mathrm{C} 3>\mathrm{C} 13>\mathrm{C} 11>\mathrm{C} 7>\mathrm{C} 15$ olarak bulunurken $\mathrm{NP}$ verilerine göre ise $\mathrm{O} 2>\mathrm{O} 1>\mathrm{N} 2>\mathrm{N} 1>\mathrm{C} 9>\mathrm{C} 8>\mathrm{C} 15>\mathrm{C} 7>\mathrm{C} 3>\mathrm{C} 13>\mathrm{C} 11>\mathrm{C} 12>\mathrm{C} 6>\mathrm{C} 14$ olarak elde edilmiştir. En pozitif yükler ise MPY ve NPY göre sirasıyla $\mathrm{C} 10>\mathrm{C} 2>\mathrm{Cu}>\mathrm{C} 1>\mathrm{C} 16$ ve $\mathrm{Cu}>\mathrm{C} 16>\mathrm{C} 1>\mathrm{C} 2>\mathrm{C} 10$ şeklinde bulunmuştur. Beklendiği üzere en negatif yükler $\mathrm{O} 1, \mathrm{O} 2$, $\mathrm{N} 1$ ve $\mathrm{N} 2$ atomları üzerinde, en pozitif yükler ise hidrojen atomları ve $\mathrm{Cu}$ atomunda yerelleşmiştir.

\begin{tabular}{cccccc}
\multicolumn{6}{c}{ Tablo 3. Çalış1lan moleküle ait Mulliken (MP) ve doğal popülasyon (NP) net yükleri } \\
\hline Atom & MP & NP & Atom & MP & NP \\
\hline C1 & 0,040976 & 0,41766 & $\mathbf{C 1 2}$ & $-0,346540$ & $-0,18803$ \\
C2 & 0,933429 & 0,18507 & $\mathbf{C 1 3}$ & $-0,134657$ & $-0,28154$ \\
C3 & $-0,145695$ & $-0,29257$ & $\mathbf{C 1 4}$ & $-0,219609$ & $-0,18044$ \\
C4 & $-0,302413$ & $-0,18263$ & $\mathbf{C 1 5}$ & $-0,085207$ & $-0,30977$ \\
C5 & $-0,149671$ & $-0,28179$ & Cl6 & 0,060108 & 0,41783 \\
C6 & $-0,203504$ & $-0,18040$ & N1 & $-0,290442$ & $-0,59607$ \\
C7 & $-0,013639$ & $-0,30971$ & $\mathbf{N 2}$ & $-0,299580$ & $-0,59630$ \\
C8 & $-0,294051$ & $-0,47289$ & $\mathbf{O 1}$ & $-0,483926$ & $-0,68617$ \\
C9 & $-0,279901$ & $-0,47291$ & $\mathbf{O 2}$ & $-0,482930$ & $-0,68620$ \\
C10 & 0,992258 & 0,17916 & $\mathbf{C u}$ & 0,167587 & 1,01776 \\
C11 & $-0,119895$ & $-0,28085$ & & & \\
\hline
\end{tabular}

\subsection{Lokal Kimyasal Aktivite: Fukui Fonksiyon (FF) Analizi}

Fukui fonksiyon analizinde nötr, anyonik ve katyonik durum için NPY yükleri hesaplanmaktadır. Hesaplanan net yüklerden aşağıda verilen eşitlikler kullanılarak her bir durum için her atoma ait fonksiyonlar hesaplanır. Bu analizin amacı nötr, anyonik ve katyonik durum için çalışılan moleküle ait atomların net yüklerinin bulunması ve yapının elektrofilik ve nükleofilik bölgelerin tespitidir. Fukui fonksiyon değerleri $\left(f_{k}^{+}(r), f_{k}^{-}(r), f_{k}^{0}(r)\right)$ fonksiyonları ile belirlenir. $f_{k}^{+}(r)$ nükleofilik atağa, $f_{k}^{-}(r)$ elektrofilik atağa ve $f_{k}^{0}(r)$ serbest radikal atağa yatkınlığı belirleyen parametrelerdir. Aşağıdaki bu fonksiyonlara ait eşitlikler verilmiştir.

$$
\begin{gathered}
f_{k}^{+}(r)=q_{k}(r)(N+1)-q_{k}(r)(N) \\
f_{k}^{-}(r)=q_{k}(r)(N)-q_{k}(r)(N-1) \\
f_{k}^{0}(r)=\frac{1}{2}\left[q_{k}(r)(N+1)-q_{k}(r)(N-1)\right]
\end{gathered}
$$

Yukarıdaki eşitlikte, $q_{k}$ atomik yükleri, $(N)$ nötr, $(N+1)$ anyonik, $(N-1)$ ise katyonik kimyasal bölgeye ait $k$ 'ıncı atomik yükleri temsil etmektedir. Hesaplamalar yapılırken anyonik, katyonik ve nötr durum için doğal bağ analizi yardımıyla her atoma ait yükler Gaussian09 paket programında oluşan OUT dosyasında elde edilerek, bu yükler üzerinden 1 ve 2 numaralı eşitlikler kullanılarak her bir atoma ait fonksiyonlar elde edilir. Yapıya ait atomların elektrofilik ve nükleofilik doğasını belirleyen parametre ise $\Delta f_{k}(r)$ 'dir. Nükleofilik ve elektrofilik FF farkı $\Delta f_{k}(r)=\left[f_{k}^{+}(r)-f_{k}^{-}(r)\right]$ ile belirlenir [18]. Eğer $\Delta f_{k}(r)>0$ ise nükleofilik yatkınlık, $\Delta f_{k}(r)<0$ ise elektrofilik yatkınlık baskındır. Çalışılan moleküle ait $\Delta f_{k}(r)<0$, elektrofilik baskın bölgeler C1, C2, C4, C5, C6, C8, C9, C10, C11, C13, C14, C16, N1, N2, O1, O2 atomlar1 üzerinde, $\Delta f_{k}(r)>0$, nükleofilik baskın bölgeler ise $\mathrm{C} 3, \mathrm{C} 7, \mathrm{C} 12, \mathrm{C} 15$ ve $\mathrm{Cu}$ atomları üzerinde yoğunlaşmıştır 
(Tablo 4). FF sonuçlarına göre bis[2-(metilamino)troponato]bakır(II) molekülünde elektrofilik doğa, nükleofilik ve nötr doğaya karşı daha baskın olduğu görülmektedir. $\mathrm{Bu}$ sonuçlar diğer lokal kimyasal aktivite parametrelerini destekler yönde bulunmuştur.

Tablo 4. NPA net yükünden elde edilmiş Fukui fonksiyon analiz değerleri

\begin{tabular}{cccccc}
\hline Atom & $\mathbf{q}_{\mathbf{k}} \mathbf{}$ & $\mathbf{q}_{\mathbf{k}}{ }^{+}$ & $\mathbf{q}_{\mathbf{k}}{ }^{-}$ & $\mathbf{f}_{\mathbf{k}}{ }^{-}$ & $\mathbf{f}_{\mathbf{k}}{ }^{+}$ \\
\hline $\mathbf{C 1}$ & 0,41766 & 0,39397 & 0,41900 & $-0,00134$ & $-0,02369$ \\
$\mathbf{C 2}$ & 0,18507 & 0,19557 & 0,15979 & 0,02528 & 0,0105 \\
$\mathbf{C 3}$ & $-0,29257$ & $-0,26564$ & $-0,31728$ & 0,02471 & 0,02693 \\
$\mathbf{C 4}$ & $-0,18263$ & $-0,15733$ & $-0,21017$ & 0,02754 & 0,0253 \\
$\mathbf{C 5}$ & $-0,28179$ & $-0,22969$ & $-0,33616$ & 0,05437 & 0,0521 \\
$\mathbf{C 6}$ & $-0,18040$ & $-0,16112$ & $-0,20307$ & 0,02267 & 0,01928 \\
$\mathbf{C 7}$ & $-0,30971$ & $-0,26979$ & $-0,34681$ & 0,0371 & 0,03992 \\
$\mathbf{C 8}$ & $-0,47289$ & $-0,47881$ & $-0,46889$ & $-0,004$ & $-0,00592$ \\
$\mathbf{C 9}$ & $-0,47291$ & $-0,47883$ & $-0,46889$ & $-0,00402$ & $-0,00592$ \\
$\mathbf{C 1 0}$ & 0,17916 & 0,18956 & 0,15979 & 0,01937 & 0,0104 \\
$\mathbf{C 1 1}$ & $-0,28085$ & $-0,25369$ & $-0,31728$ & 0,03643 & 0,02716 \\
$\mathbf{C 1 2}$ & $-0,18803$ & $-0,16281$ & $-0,21017$ & 0,02214 & 0,02522 \\
$\mathbf{C 1 3}$ & $-0,28154$ & $-0,22943$ & $-0,33617$ & 0,05463 & 0,05211 \\
$\mathbf{C 1 4}$ & $-0,18044$ & $-0,16117$ & $-0,20306$ & 0,02262 & 0,01927 \\
$\mathbf{C 1 5}$ & $-0,30977$ & $-0,26987$ & $-0,34681$ & 0,03704 & 0,0399 \\
$\mathbf{C 1 6}$ & 0,41783 & 0,39413 & 0,41901 & $-0,00118$ & $-0,0237$ \\
$\mathbf{N 1}$ & $-0,59607$ & $-0,52876$ & $-0,56201$ & 0,26594 & 0,06754 \\
$\mathbf{N 2}$ & $-0,59630$ & $-0,6636$ & $-0,56201$ & $-0,03429$ & $-0,0673$ \\
$\mathbf{O 1}$ & $-0,68617$ & $-0,78118$ & $-0,68149$ & $-0,00468$ & $-0,09501$ \\
$\mathbf{O 2}$ & $-0,68620$ & $-0,78121$ & $-0,68148$ & $-0,00472$ & $-0,09501$ \\
$\mathbf{C u}$ & 1,01776 & 1,08804 & 0,94787 & 0,06989 & 0,07028 \\
\hline
\end{tabular}

\section{6. İkinci Dereceden Çizgisel Olmayan Optik Özellikler (NLO)}

Son yıllarda, NLO materyaller birçok bilim alanında yaygın kullanımlarından dolayı oldukça ilgi çekici olmuştur. İyi NLO özellik gösteren organik, inorganik ve organometalik materyaller optik iletişimde, sinyal işlemede, optik hesaplamada, sensörlerde, optik bağlantı materyallerinin tasarımında ve diğer birçok fotonik teknolojide etkili bir şekilde kullanılmaktadır [19]. Yalıtılmış bir molekül üzerine dışarıdan bir elektrik alan uygulandığında molekülün dipol momenti yeniden şekillenir. Bunun sonucunda toplam dipol moment ifadesinde kalıcı dipol moment dişında birinci ve ikinci mertebeden katkılar ortaya çıkar. Uygulanan elektrik alan zayıfsa doğrusal optik özellikleri temsil eden, moleküler kutuplanabilirlik, $\alpha$, dikkate alınırken daha şiddetli elektrik alan uygulanması durumunda doğrusal olmayan optik özellikleri temsil eden birinci dereceden hiperkutuplanabilirlik, $\beta$, önemli hale gelir. Bir molekülün doğrusal olmayan optik özelliklerini Gaussian09 paket programı kullanarak hesaplamak için optimize molekül üzerinden enerji hesabı yapılır ve anahtar kelime kısmına POLAR=ENONLY ifadesi yazılırak hesaplama başlatılır. Daha sonra çıkış dosyasından moleküler kutuplanabilirliğin ortalama değeri, kartezyen koordinatlar kullanılarak,

$$
\alpha=\frac{\alpha_{\mathrm{xx}}+\alpha_{\mathrm{yy}}+\alpha_{\mathrm{zz}}}{3}
$$

birinci dereceden hiperkutuplanabilirlik ise

$$
\beta_{\mathrm{tot}}=\left[\left(\beta_{\mathrm{xxx}}+\beta_{\mathrm{xyy}}+\beta_{\mathrm{xzz}}\right)^{2}+\left(\beta_{\mathrm{yyy}}+\beta_{\mathrm{yzz}}+\beta_{\mathrm{yxx}}\right)^{2}+\left(\beta_{\mathrm{zzz}}+\beta_{\mathrm{zxx}}+\beta_{\mathrm{zyy}}\right)^{2}\right]^{1 / 2}
$$


şeklinde hesaplanır. Moleküllerin HOMO-LUMO enerji aralığı ve doğrusal olmayan optik özellikleri arasında sıkı bir ilişki vardır [20]. Bu enerji aralığı daraldıkça uygulanan elektrik alan yardımı ile HOMO' dan LUMO' ya elektron göçünün daha kolay olacağ1 söylenebilir. Elektron dağılımının kolay değişebilmesi kutuplanmayı artırır ve böylece $\beta$ değeri de artar. Ayrıca molekülün uçlarına alıcı-verici gurupların bağlanması da yük asimetrisini etkiler ve $\beta$ değeri artar. Bunların dışında $\pi$ bağındaki elektronların kutuplanabilirliğine bağlı olan $\beta$ değeri, konjuge $\pi$ bağları artırılarak molekül uzatıldığında da artacaktır. Bis[2-(metilamino)troponato]bakır(II) molekülünün moleküler kutuplanabilirlik ve birinci dereceden hiperkutuplanabilirlik değerleri YFK/B3LYP/6-31++G(d,p) seviyesinde hesaplanmıştır. Hesaplanan moleküler kutuplanabilirlik , $\alpha$, ve birinci dereceden hiperkutuplanabilirlik, $\beta$, değerleri atomik birimden (a.u.) elektrostatik birime (e.s.u.) çevrilerek sırasıyla $42.7378 \AA^{3}, 14.8222 \times 10^{-}$ ${ }^{33}$ esu olarak elde edilmiştir. Prototipik bir NLO materyali olan üre ile karşılaştırıldığında elde edilen $\beta$ değerinin, oldukça düşük olduğu elde edilmiştir [21,22].

\subsection{Doğal Bağ Orbital (NBO) Analizi}

Moleküller arasındaki etkileşimlerinin anlaşılmasında sıklıkla kullanılan bir yöntem olan doğal bağ orbital analizi (NBO) GaussianO9 program paketi içinde mevcut olan program kullanılarak hesaplanmaktadır. Bu analiz ile farklı bağlardaki $\sigma$ ve $\pi$ bağları için ayrı ayrı bağ elektron bulunma yüzdeleri ile her atomun üzerindeki elektronların $s$, p ve d orbitallerinde bulunma yüzdelerindeki değişimler elde edilmektedir. Bu yöntem ile atomlar üzerinde bağ yapmak üzere oluşan hibritleşmeler de elde edilmektedir. Bunların yanı sıra NBO analizi ile orbitallerin stabiliazyon enerjileri $\mathrm{E}^{(2)}$, orbitaller arasındaki etkileşim enerjileri ve geçiş durumları incelenmektedir. Bilindiği üzere $\pi$ bağları tabiatları gereği $\mathrm{C}, \mathrm{O}$ ve $\mathrm{N}$ atomlarının $\mathrm{p}$ atomik orbitallerinden oluşması gerekir. $\mathrm{C}$ atomunda oluşan melezleşmede $\sigma$ bağında s orbitalinin katkı miktarının $\pi$ orbitalleri lehine azaldığ 1 görülmüştür [23, 24]. $\mathrm{O}$ atomlarında ise bu değişim $\mathrm{C}$ atomlarına göre çok daha az olmuştur. Bu değişimler $\pi$ bağları için tahmin edileceği gibi nerdeyse yok gibidir. $\mathrm{Bu}$ verilere ait analiz sonuçları Tablo 5'de verilmiştir. Optimize bis[2(metilamino)troponato]bakır(II) molekülüne ait NBO analizi sonucunda toplam Lewis orbital $96.736 \%$, Lewis olmayan orbital $3.264 \%$, çekirdek orbital $99.968 \%$, valans Lewis orbital $95.092 \%$, valas Lewis olmayan orbital 3.086\% ve Rydberg Lewis olmayan orbital ise $0.178 \%$ olarak hesaplanmıştır.

Moleküller arası hiperkonjugatif etkileşimler bağ ve antibağ orbitalleri arasında orbitallerin örtüşmesiyle moleküler sistemin kararlılığına sebep olarak moleküller arası yük transferine izin verir. $\mathrm{Bu}$ etkileşimler bağ karakterini zayıflatarak, antibağ orbitallerinde alaktron yoğunluğunun artışına yol açar. Bu bağlar incelenen molekülde geçiş durumları ve enerji değerleri ile birlikte $\pi(\mathrm{C} 16-\mathrm{C} 15) \rightarrow \pi^{*}(\mathrm{C} 10-\mathrm{C} 11) 6.51 \mathrm{kcal} / \mathrm{mol}$, $\pi(\mathrm{C} 10-\mathrm{C} 11) \rightarrow \pi^{*}(\mathrm{C} 12-\mathrm{C} 13) 11.98 \mathrm{kcal} / \mathrm{mol}, \pi(\mathrm{C} 12-\mathrm{C} 13) \rightarrow \pi^{*}(\mathrm{C} 10-\mathrm{C} 11) 8.70 \mathrm{kcal} / \mathrm{mol}$ ve $\pi(\mathrm{C} 1-\mathrm{C} 7) \rightarrow \pi^{*}(\mathrm{C} 5-\mathrm{C} 6) 13.40 \mathrm{kcal} / \mathrm{mol}$ olarak gözlenmiştir. En güçlü etkileşimler $\pi(\mathrm{C} 16-\mathrm{C} 15) \rightarrow \mathrm{n}^{*}(\mathrm{C} 14), \quad \pi(\mathrm{C} 12-\mathrm{C} 13) \rightarrow \mathrm{n}^{*}(\mathrm{C} 14), \quad \mathrm{n} *(\mathrm{C} 13) \rightarrow \pi^{*}(\mathrm{C} 16-\mathrm{C} 15)$, $\mathrm{n}^{*}(\mathrm{C} 13) \rightarrow \pi^{*}(\mathrm{C} 12-\mathrm{C} 13), \quad \mathrm{n} *(\mathrm{~N} 2) \rightarrow \pi^{*}(\mathrm{C} 10-\mathrm{C} 11), \quad \mathrm{n}^{*}(\mathrm{O} 2) \rightarrow \pi^{*}(\mathrm{C} 16-\mathrm{C} 15)$, $\mathrm{n} *(\mathrm{~N} 1) \rightarrow \mathrm{n} *(\mathrm{C} 2), \mathrm{n} *(\mathrm{O} 1) \rightarrow \pi^{*}(\mathrm{C} 1-\mathrm{C} 7)$ ile sirasiyla 33.05, 30.99, 28.19, 24.01, 38.42, $29.78,122.97$ ve $29.78 \mathrm{kcal} / \mathrm{mol}$ olan kararlılık enerji verileri ile gözlenmiştir. Tablo 5 'de diğer donor ve akteptöre ait doluluk değerleri ve enerji değerleri verilmiştir. 
Tablo 5. Çalışılan moleküle ait NBO analiz değerleri

\begin{tabular}{|c|c|c|c|c|c|c|c|c|}
\hline $\begin{array}{l}\text { Donör }(i) \\
(\text { doluluk) }\end{array}$ & Tip & $\begin{array}{l}E D_{A}, \% \\
E D_{B}, \%\end{array}$ & $\begin{array}{c}\text { Akseptör }(j) \\
(\text { doluluk })\end{array}$ & Tip & $\begin{array}{l}E D_{A}, \% \\
E D_{B}, \%\end{array}$ & $\begin{array}{c}E^{(2) a} \\
(\mathrm{kcal} / \mathrm{mol})\end{array}$ & $\begin{array}{l}E_{j}-E_{i}^{b} \\
\text { (a.u.) }\end{array}$ & $F(i j)^{c}(a . u)$. \\
\hline $\begin{array}{c}\text { BDC16-C15 } \\
(0.78386)\end{array}$ & $\pi$ & $\begin{array}{l}41.58 \\
58.42\end{array}$ & $\begin{array}{c}\mathrm{LP} * \mathrm{C} 14 \\
(0.47048)\end{array}$ & $n^{*}$ & $\begin{array}{l}51.09 \\
48.91\end{array}$ & 33.05 & 0.14 & 0.099 \\
\hline $\begin{array}{c}\text { BDC16-C15 } \\
(0.78386)\end{array}$ & $\pi$ & $\begin{array}{l}41.58 \\
58.42\end{array}$ & $\begin{array}{c}\mathrm{BD} * \mathrm{C} 10-\mathrm{C} 11 \\
(0.22629)\end{array}$ & $\pi^{*}$ & $\begin{array}{l}56.74 \\
43.26\end{array}$ & 6.51 & 0.27 & 0.053 \\
\hline $\begin{array}{c}\text { BDC10-C11 } \\
(0.75932)\end{array}$ & $\pi$ & $\begin{array}{l}43.26 \\
56.74\end{array}$ & $\begin{array}{c}\mathrm{BD}^{*} \mathrm{C} 12-\mathrm{C} 13 \\
(0.19381)\end{array}$ & $\pi^{*}$ & $\begin{array}{l}54.12 \\
45.88\end{array}$ & 11.98 & 0.32 & 0.081 \\
\hline $\begin{array}{c}\text { BD C11-H11 } \\
(0.98697)\end{array}$ & $\sigma$ & $\begin{array}{l}61.98 \\
38.02\end{array}$ & $\begin{array}{c}\mathrm{BD} * \mathrm{C} 16-\mathrm{C} 10 \\
(0.03221)\end{array}$ & $\sigma^{*}$ & $\begin{array}{l}51.09 \\
48.91\end{array}$ & 2.78 & 0.96 & 0.066 \\
\hline $\begin{array}{c}\text { BD C12-H12 } \\
(0.98811)\end{array}$ & $\sigma$ & $\begin{array}{l}61.86 \\
38.14\end{array}$ & $\begin{array}{c}\mathrm{BD} * \mathrm{C} 10-\mathrm{C} 11 \\
(0.01669)\end{array}$ & $\sigma^{*}$ & $\begin{array}{l}48.89 \\
51.11\end{array}$ & 3.23 & 1.05 & 0.074 \\
\hline $\begin{array}{c}\text { BD C12-C13 } \\
(0.80057)\end{array}$ & $\pi$ & $\begin{array}{l}45.88 \\
54.12\end{array}$ & $\begin{array}{c}\mathrm{LP} * \mathrm{C} 14 \\
(0.47048)\end{array}$ & $n^{*}$ & - & 30.99 & 0.14 & 0.096 \\
\hline $\begin{array}{c}\text { BD C12-C13 } \\
(0.80057)\end{array}$ & $\pi$ & $\begin{array}{l}45.88 \\
54.12\end{array}$ & $\begin{array}{c}\mathrm{BD} * \mathrm{C} 10-\mathrm{C} 11 \\
(0.22629)\end{array}$ & $\pi^{*}$ & $\begin{array}{l}56.74 \\
43.26\end{array}$ & 8.70 & 0.27 & 0.062 \\
\hline $\begin{array}{c}\text { BD C9-H9a } \\
(0.99461)\end{array}$ & $\sigma$ & $\begin{array}{l}62.78 \\
37.22\end{array}$ & $\begin{array}{c}\mathrm{BD} * \mathrm{C} 10-\mathrm{N} 2 \\
(0.00972)\end{array}$ & $\sigma^{*}$ & $\begin{array}{l}59.33 \\
40.67\end{array}$ & 1.85 & 1.05 & 0.056 \\
\hline $\begin{array}{c}\text { CR C2 } \\
(0.99952)\end{array}$ & - & - & $\begin{array}{c}\mathrm{BD} * \mathrm{C} 9-\mathrm{N} 2 \\
(0.00632)\end{array}$ & $\sigma *$ & $\begin{array}{l}61.24 \\
38.76\end{array}$ & 0.59 & 10.47 & 0.099 \\
\hline $\begin{array}{c}\text { CR O2 } \\
(1.97217)\end{array}$ & - & - & $\begin{array}{l}\text { RY*C16 } \\
(0.03175)\end{array}$ & - & - & 1.86 & 19.92 & 0.244 \\
\hline $\begin{array}{c}\text { CR N2 } \\
(0.99969)\end{array}$ & - & - & $\begin{array}{c}\mathrm{BD} * \mathrm{C} 10-\mathrm{C} 11 \\
(0.01669)\end{array}$ & $\sigma^{*}$ & $\begin{array}{l}48.89 \\
51.11\end{array}$ & 0.43 & 14.40 & 0.101 \\
\hline $\begin{array}{l}\text { LP* C } 13 \\
(0.47048)\end{array}$ & $n^{*}$ & - & $\begin{array}{c}\mathrm{BD} * \mathrm{C} 16-\mathrm{C} 15 \\
(0.16790)\end{array}$ & $\pi^{*}$ & $\begin{array}{l}58.42 \\
41.58\end{array}$ & 28.19 & 0.14 & 0.098 \\
\hline $\begin{array}{l}\text { LP* C13 } \\
(0.47048)\end{array}$ & $n^{*}$ & - & $\begin{array}{c}\mathrm{BD} * \mathrm{C} 12-\mathrm{C} 13 \\
(0.19381)\end{array}$ & $\pi^{*}$ & $\begin{array}{l}54.12 \\
45.88\end{array}$ & 24.01 & 0.19 & 0.104 \\
\hline $\begin{array}{c}\text { LP N2 } \\
(0.73378)\end{array}$ & $n$ & - & $\begin{array}{c}\mathrm{BD} * \mathrm{C} 10-\mathrm{C} 11 \\
(0.22629)\end{array}$ & $\pi^{*}$ & $\begin{array}{l}56.74 \\
43.26\end{array}$ & 38.42 & 0.23 & 0.121 \\
\hline $\begin{array}{c}\text { LP O2 } \\
(0.97420)\end{array}$ & $n$ & - & $\begin{array}{c}\mathrm{BD} * \mathrm{C} 16-\mathrm{C} 10 \\
(0.03221)\end{array}$ & $\sigma^{*}$ & $\begin{array}{l}51.09 \\
48.91\end{array}$ & 4.65 & 0.97 & 0.085 \\
\hline $\begin{array}{c}\text { LP O2 } \\
(0.97420)\end{array}$ & $n$ & - & $\begin{array}{c}\mathrm{BD} * \mathrm{C} 16-\mathrm{C} 15 \\
(0.16790)\end{array}$ & $\pi^{*}$ & $\begin{array}{l}58.42 \\
41.58\end{array}$ & 29.78 & 0.30 & 0.119 \\
\hline $\begin{array}{c}\mathrm{BD} * \mathrm{C} 10-\mathrm{C} 11 \\
(0.22629)\end{array}$ & $n^{*}$ & $\begin{array}{l}56.74 \\
43.26\end{array}$ & $\begin{array}{c}\mathrm{BD}^{*} \mathrm{C} 12-\mathrm{C} 13 \\
(0.19381)\end{array}$ & $\pi^{*}$ & $\begin{array}{l}54.12 \\
45.88\end{array}$ & 21.25 & 0.05 & 0.065 \\
\hline $\begin{array}{l}\text { BD C1-C7 } \\
(0.78387)\end{array}$ & $\pi$ & $\begin{array}{l}41.58 \\
58.42\end{array}$ & $\begin{array}{c}\mathrm{LP} * \mathrm{C} 2 \\
(0.45718)\end{array}$ & $n^{*}$ & - & 17.11 & 0.14 & 0.070 \\
\hline $\begin{array}{l}\text { BD C } 1-C 7 \\
(0.78387)\end{array}$ & $\pi$ & $\begin{array}{l}41.58 \\
58.42\end{array}$ & $\begin{array}{c}\mathrm{BD} * \mathrm{C} 5-\mathrm{C} 6 \\
(0.16132)\end{array}$ & $\pi^{*}$ & $\begin{array}{l}46.13 \\
53.87\end{array}$ & 13.40 & 0.28 & 0.080 \\
\hline $\begin{array}{l}\text { BDC3-C4 } \\
(0.85386)\end{array}$ & $\pi$ & $\begin{array}{l}54 \\
46\end{array}$ & $\begin{array}{c}\mathrm{LP} * \mathrm{C} 2 \\
(0.45718)\end{array}$ & $n^{*}$ & - & 23.27 & 0.15 & 0.089 \\
\hline $\begin{array}{c}\mathrm{LP} * \mathrm{C} 2 \\
(0.45718)\end{array}$ & $n^{*}$ & - & $\begin{array}{c}\mathrm{BD} * \mathrm{C} 1-\mathrm{C} 7 \\
(0.16789)\end{array}$ & $\pi^{*}$ & $\begin{array}{l}58.42 \\
41.58\end{array}$ & 24.73 & 0.14 & 0.093 \\
\hline $\begin{array}{c}\text { LP N1 } \\
(0.73378)\end{array}$ & $n$ & - & $\begin{array}{c}\mathrm{LP} * \mathrm{C} 2 \\
(0.45718)\end{array}$ & $n^{*}$ & - & 122.97 & 0.09 & 0.149 \\
\hline $\begin{array}{c}\text { LP O1 } \\
(0.82916)\end{array}$ & $n$ & - & $\begin{array}{c}\mathrm{BD} * \mathrm{C} 1-\mathrm{C} 7 \\
(0.16789)\end{array}$ & $\pi^{*}$ & $\begin{array}{l}58.42 \\
41.58\end{array}$ & 29.78 & 0.30 & 0.119 \\
\hline $\begin{array}{c}\text { LP O1 } \\
(0.93101)\end{array}$ & $n$ & - & $\begin{array}{c}\mathrm{LP} * \mathrm{Cu} \\
(0.15938)\end{array}$ & $n^{*}$ & - & 18.19 & 0.57 & 0.135 \\
\hline $\begin{array}{c}\text { CR N1 } \\
(0.99969)\end{array}$ & - & - & $\begin{array}{l}\mathrm{LP}^{*} \mathrm{Cu} \\
(0.15938)\end{array}$ & $n^{*}$ & - & 1.68 & 14.42 & 0.202 \\
\hline $\begin{array}{l}\text { BDC2-N1 } \\
(0.99285)\end{array}$ & $\sigma$ & $\begin{array}{l}40.67 \\
59.33\end{array}$ & $\begin{array}{c}\mathrm{LP} * \mathrm{Cu} \\
(0.15938)\end{array}$ & $n^{*}$ & - & 2.08 & 1.11 & 0.062 \\
\hline $\begin{array}{l}\mathrm{BDC} 1-\mathrm{O} 1 \\
(0.99606)\end{array}$ & $\sigma$ & $\begin{array}{l}34.67 \\
65.33\end{array}$ & $\begin{array}{c}\mathrm{LP} * \mathrm{Cu} \\
(0.15938)\end{array}$ & $n^{*}$ & - & 2.25 & 1.23 & 0.068 \\
\hline $\begin{array}{c}\mathrm{CR} \mathrm{Cu} \\
(0.99945)\end{array}$ & - & - & $\begin{array}{c}\mathrm{BD} * \mathrm{C} 16-\mathrm{O} 2 \\
(0.00707)\end{array}$ & $\sigma^{*}$ & $\begin{array}{l}65.33 \\
34.67\end{array}$ & 0.28 & 6.41 & 0.054 \\
\hline
\end{tabular}

\subsection{Hirshfeld Yüzey Analizi}

Hirshfeld yüzey analizi moleküller arası etkileşimleri inceleyen bir yöntemdir. Hirshfeld yüzeyleri Van der Waals mesafelerini görselleştirmek için ve moleküller arası etkileşim noktalarını belirlemek için kullanılır. Bunun yanı sıra molekülde bulunan atomların 
birbirleri ile olan etkileşimlerin yüzdesini belirleyen 2-boyutlu parmak izi tayini de Hirshfeld yüzey analizi ile yapılmaktadır [25]. Hirshfeld yüzey haritaları $d_{n o r m}, d_{i}, d_{e}$, şekil indeksi ve eğrilik indeksi haritalarını içerir. En temel yüzey haritası $d_{n o r m}$ fonksiyonu ile görselleştirilmektedir. $d_{i}$, Hirshfeld yüzeyinden yüzey içindeki en yakın atoma olan uzaklığı temsil ederken $d_{\mathrm{e}}$ bu yüzeyden yüzeyin dışındaki en yakın atoma olan mesafeyi temsil etmektedir. Yüzey üzerinde görselleştirilen renk kodları kırmızı, mavi ve beyazdır. Kırmızı renkli bölgeler Van der Waals yarıçapı toplamından daha kısa olan temas bölgelerini göstermektedir ve negatif $d_{\text {norm }}$ değerine sahiptir. Mavi renkli bölgelerde ise moleküller arası mesafe Van der Waals yarıçapları toplamından daha uzundur.

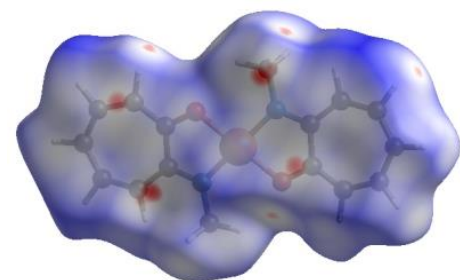

a)

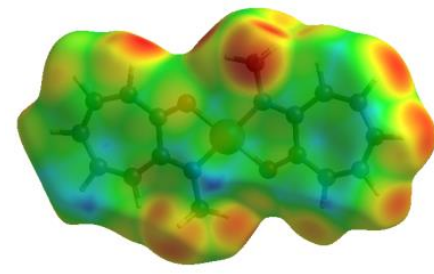

b)

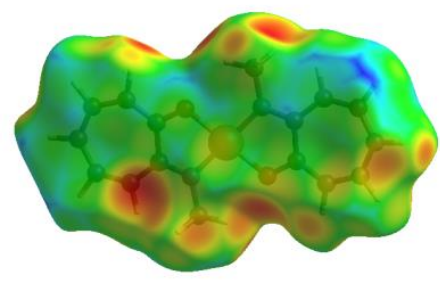

c)

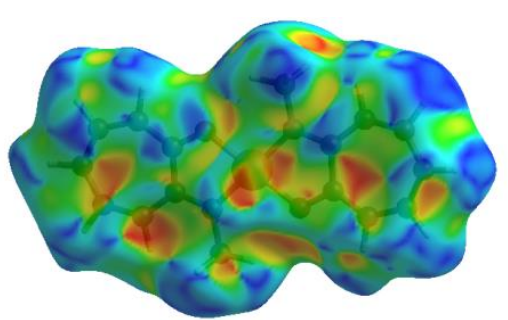

c)

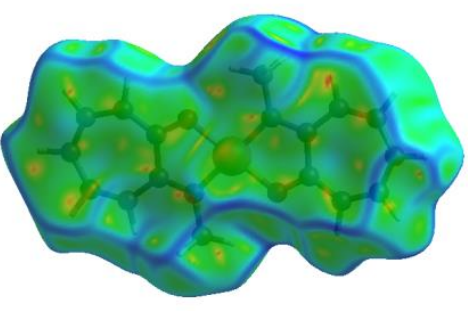

e)

Şekil 4. Hirshfeld yüzeyine ait a) $d_{\text {norm, b) }} d_{i}$, c) $d_{e}$, d) şekil indeksi ve e) eğrilik indeksi haritası

Beyaz bölgelerde moleküller arası mesafeler Van der Waals yarıçapları toplamına eşittir ve $d_{\text {norm }}$ Sıfıra eşittir. $d_{\text {norm }}$ eşitliği aşağıda verilmiş olup,

$$
d_{n o r m}=\frac{d_{i}-d_{i}^{r d w}}{d_{i}^{r d w}}+\frac{d_{e}-d_{e}^{r d w}}{d_{e}^{r d w}}
$$

moleküller arası hidrojen bağları için özel önem taşıyan bölgelerin belirlenmesini sağlar.

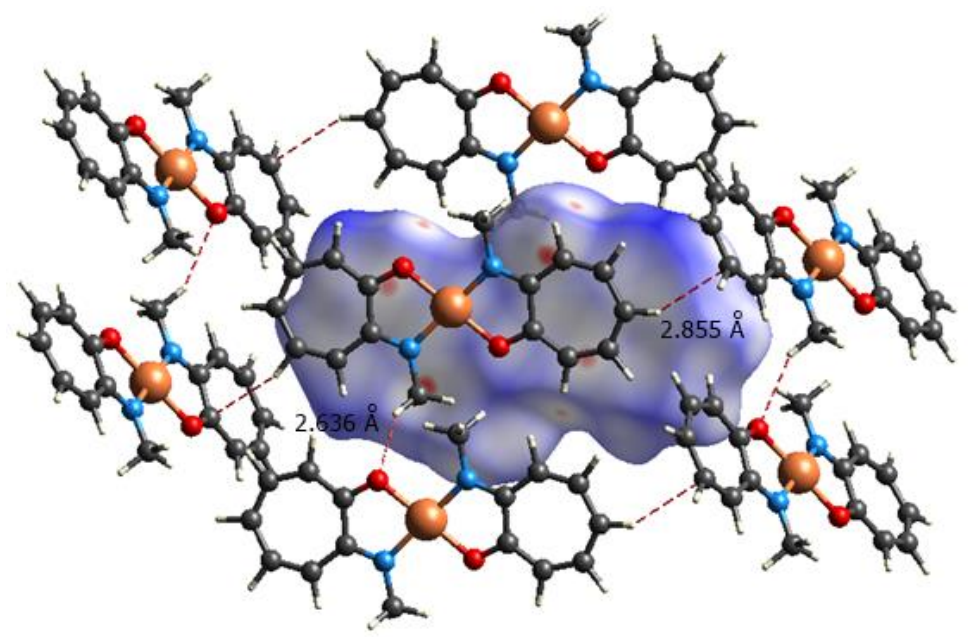

Şekil 5. $d_{\text {norm }}$ Hirshfeld yüzeyi üzerinde hidrojen bağları görünümü 
$d_{\text {norm }}, d_{i}, d_{e}$, yüzey indeks ve eğrilik indeksine ait haritalar Şekil 4'de verilmiştir. $d_{\text {norm }}, d_{i}$ ve $d_{e}$ yüzeylerine ait indisler sırasıyla -0,1020 ile 1,1893, 1,0351 ile 2,5562 ve 1,0364 ile 2,5089 aralığında elde edilmiştir. Şekil indeksi ve eğrilik indeksi ise sırasıyla -1 ile 1 ve -4 ile 4 aralığında gözlenmiştir (Şekil 4). Şekil indeksi ise moleküller arasında düzlemsel olarak meydana gelen $\pi . . . \pi$ etkileşmelerini betimler. Bu etkileşimler, Hirshfeld yüzeyinin şekil indeksinde kırmızı ve mavi renkli birbirine bitişik üçgenler ile temsil edilir.

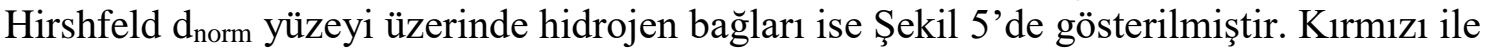
gösterilen bölgeler hidrojen bağlarının varlığını açık bir şekilde kanıtlamıştır. 2-boyutlu parmak izine ait gösterim ise Şekil 6'de verilmiştir. Toplam Hirshfeld yüzeyine ait en büyük katkılar C...H/H...C $(21,6 \%)$ ve H...H/H...H (52,9\%) etkileşimlerine aittir. Diğer katk1lar ise $\mathrm{C} \ldots \mathrm{C} / \mathrm{C} \ldots \mathrm{C}(7,4 \%), \quad \mathrm{N} \ldots \mathrm{H} / \mathrm{H} \ldots \mathrm{N} \quad(2,8 \%), \mathrm{O} \ldots \mathrm{H} / \mathrm{H} \ldots \mathrm{O} \quad(7,6 \%)$ ve $\mathrm{Cu} \ldots \mathrm{O} / \mathrm{O} \ldots \mathrm{Cu}(2,4 \%)$ arasında gözlenmiştir.
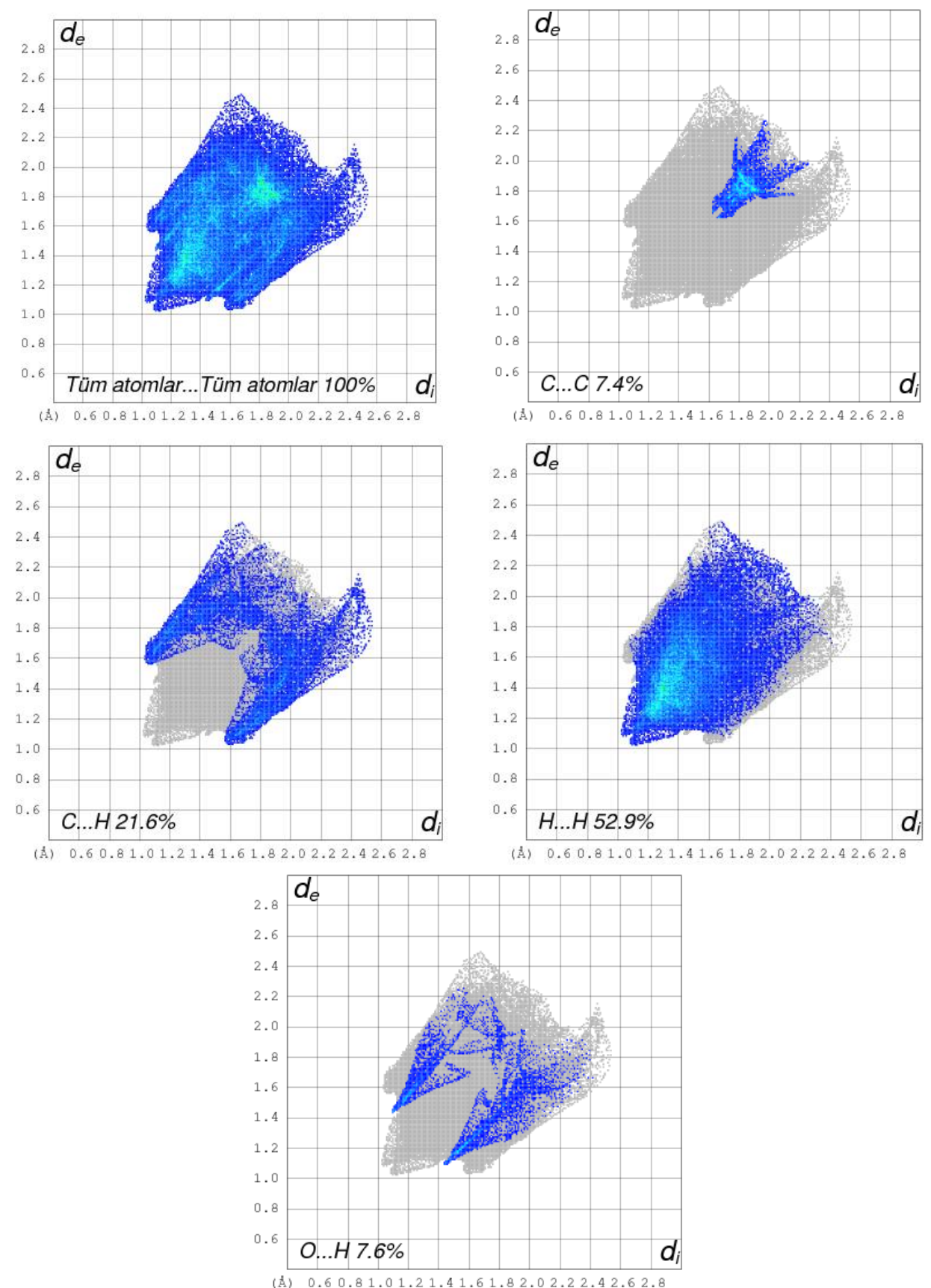

Şekil 6. Çalışılan moleküle ait 2-boyutlu parmak izi gösterimi 


\section{Sonuç ve Yorum}

Bis[2-(metilamino)troponato]bakır(II) molekülün lokal ve global kimyasal aktivite parametreleri kuramsal olarak YFK/B3LYP/6-31++G(d,p) yöntemi ile incelenmiştir. Optimizasyon sonucunda elde edilen geometrik parametreler literatürde bulunan X-1şını kırınımı deneyi sonucunda elde edilen verilerle karşılaştırıldığında oldukça başarılı bir seçim olduğu bulunmuştur. Global kimyasal aktivite parametreleri öncü moleküler orbital olan HOMO ve LUMO enerjilerinin hesaplanması sonucunda elde edilmiştir. Moleküle ait $\alpha$ ve $\beta$ spinlerine ait düşük sertlik ve yüksek yumuşaklık parametreleri ( $\alpha$ için sertlik ve yumuşaklık paramereleri sırasıyla $1,806 \mathrm{eV}, 0,276(\mathrm{eV})^{-1} ; \beta$ için ise sırasıyla 1,548 eV, $\left.0,322(\mathrm{eV})^{-1}\right)$ yapının yüksek kimyasal aktivite ve düşük kinetik stabilite ile kimyasal aktiviteye yatkın olduğunu göstermiştir. Fukui analizi sonucunda elektrofilik baskın bölgeler C1, C2, C4, C5, C6, C8, C9, C10, C11, C13, C14, C16, N1, N2, O1, O2 atomlar1 üzerinde, nükleofilik baskın bölgeler ise $\mathrm{C} 3, \mathrm{C} 7, \mathrm{C} 12, \mathrm{C} 15$ ve $\mathrm{Cu}$ atomları üzerinde yoğunlaşmıştır. MEP haritasında en negatif bölgeler oksijen atomları üzerinde kırmızı ile kodlanmıştır ve bu bölgeler hidrojen bağlarının oluşumunda aktif olan ve elektrofilik yatkınlığı fazla olan bölgeleri temsil etmektedir. Nükleofilik doğanın baskın olduğu bölgeler ise metil ve hidrojen atomlarının yoğun olduğu bölgelerde yerelleşmiş konumda bulunmaktadır. MEP, net yükler ve Fukui fonksiyon analizi sonuçları birbirini desteklediği öngörülmüştür. Yapılan lineer olmayan optik özellik analizi ile moleküler kutuplanabilirlik ve birinci dereceden hiperkutuplanabilirlik değerleri sirasıyla 42,7378 $\AA^{3}, 14,8222 \times 10^{-33}$ esu olarak elde edilmiştir. Elde edilen $\beta$ değeri, molekülün optik bir materyal olmaya iyi bir aday olduğunu göstermemektedir. Doğal bağ orbital analizi ile kararlılık enerjisi, bağlardaki $\sigma$ ve $\pi$ bağları için ayrı ayrı bağ elektron bulunma yüzdeleri ve orbitallerin geçiş durumları incelenmiştir. Hirshfeld yüzey analizi sonucunda Hirsfeld yüzey haritaları oluşturulmuştur ve 2-boyutlu parmak izi bölgesi tayini sonucunda atomlar arasındaki en büyük etkileşimler C...H/H...C (21,6\%) ve H...H/H...H $(52,9 \%)$ olarak bulunmuştur. Hirshfeld yüzey haritaları ile moleküler yapının paket yapısı ve moleküler etkileşimleri elde edilerek görsel hale getirilmiştir.

\section{Araştırmacıların Katkı Oranı Beyanı}

Serap UZUN: Araştırma, Orijinal Taslak Yazımı.

Zeynep DEMİRCİOĞLU: Araştırma, Doğrulama, İnceleme ve Düzenleme.

\section{Destek ve Teşekkür Beyanı}

Bu çalışmanın yazarları olarak herhangi bir destek ve teşekkür beyanımız bulunmadığını bildiririz.

\section{Çatışma Beyanı}

Bu çalışmanın yazarları olarak herhangi bir çatışma beyanımız bulunmadığını bildiririz.

\section{Etik Kurul Onayı ve/veya Aydınlatılmış Onam Bilgileri}

$\mathrm{Bu}$ çalışmanın yazarları olarak herhangi bir etik kurul onayı ve/veya aydınlatılmış onam bilgileri beyanımız bulunmadığını bildiririz.

\section{Kaynakça}

[1] G. Steyl, T.J. Muller and A. Roodt, "Bis[2-(methylamino)troponato]copper(II)," Acta Cryst., E66, m1508, 2010.

[2] Y.-C. Liang, M.-C.,Hong, R. Cao, and Q. Shi, "Bis(pyridine-2,4-dicarboxylato)copper(II) dihydrate," Acta Cryst. E57, m380-m381, 2001.

[3] Z. A. Starikova and E. A. Shugam, "Crystal chemical data for inner complexes of $\beta$-diketones," $Z$ h. Strukt. Khim., 10, 290-293, 1969.

[4] M. P. Byrn, C. J. Curtis, Y.Hsiou, S.I. Khan, P.A. Sawin, S.K. Tendick, A. Terzis, C.E. Strouse, J. Am. Chem. Soc., "Porphyrin sponges: Conservation of host structure in over 200 porphyrin-based lattice clathrates," 115, 9480-9497, 1993. 
[5] K. H. Park and W.J. Marshall, "Routes to N,N'-unsymmetrically substituted 1,3-diketimines,” J. Am. Chem. Soc., 127, 9330-9331, 2005.

[6] I. A. Baidina, P. A. Stabnikov, A. D. Vasil'ev, S. A. Gromilov, and I. K. Igumenov, “Crystal and molecular structure of copper(II)trans-bis-(2-(methylimino)-4-pentanonate)," Zh. Strukt. Khim., 45, 671-677, 2004.

[7] GaussView, Version 5, R. Dennington, T. Keith and J. Millam, Semichem Inc., Shawnee Mission KS, 2009.

[8] M.J. Frisch, G.W. Trucks, H.B. Schlegel, G.E. Scuseria, M.A. Robb, J.R. Cheeseman, G. Scalmani, V. Barone, B. Mennucci, G.A. Petersson, H. Nakatsuji, M. Caricato, X. Li, H.P. Hratchian, A.F. Izmaylov, J. Bloino, G. Zheng, J.L. Sonnenberg, M. Hada, M. Ehara, K. Toyota, R. Fukuda, J. Hasegawa, M. Ishida, T. Nakajima, Y. Honda, O. Kitao, H. Nakai, T. Vreven, J.A. MontgomeryJr., J.E. Peralta, F. Ogliaro, M. Bearpark, J.J. Heyd, E. Brothers, K.N. Kudin, V.N. Staroverov, R. Kobayashi, J. Normand, K. Raghavachari, A. Rendell, J.C. Burant, S.S. Iyengar, J. Tomasi, M. Cossi, N. Rega, J.M. Millam, M. Klene, J.E. Knox, J.B. Cross, V. Bakken, C. Adamo, J. Jaramillo, R. Gomperts, R.E. Stratmann, O. Yazyev, A.J. Austin, R. Cammi, C. Pomelli, J.W. Ochterski, R.L. Martin, K. Morokuma, V.G. Zakrzewski, G.A. Voth, P. Salvador, J.J. Dannenberg, S. Dapprich, A.D. Daniels, O. Farkas, J.B. Foresman, J.V. Ortiz, J. Cioslowski, and D.J. Fox, Gaussian 09W, Revision E.01, Gaussian, Inc., Wallingford CT, 2009.

[9] D. J. G. S. K. Wolff, J. J. McKinnon, M. J. Turner, D. Jayatilaka, and M. A. Spackman, CrystalExplorer, 2012, Version3.1.

[10] B.-Y. Zhang, Q. Yang, and J.-J. Nie, “ Bis(pyrimidine-2-carboxylato-Ḱ ${ }^{2} N, O$ )copper(II), ${ }^{\text {Acta }}$ Cryst. E64, m7, 2008.

[11] T. N. Hill and G. Steyl, " Dicarbonyl[2-hydroxy-3,5,7-tris(morpholinomethyl)cyclohepta-2,4,6-trienonato(1-)- $\left.\kappa^{2} \mathrm{O}^{1}, \mathrm{O}^{2}\right]$ rhodium(I)," Acta Cryst., E64, m1580-m1581, 2008.

[12] O. Kristiansson, "Bis(pyrazine-2-carboxamide)bis(trifluoromethanesulfonato)copper(II) monohydrate," Acta Cryst., E58, m130-m132, 2002.

[13] K. Bahgat and S. Fraihat, "Normal coordinateanalysis, molecularstructure, vibrational, electronicspectraand NMR investigation of 4-amino-3-phenyl-1 $H$-1,2,4-triazole-5(4H)-thioneby $a b$ initio HF and DFT method," Spectrochim. Acta A, 135, 1145-1155, 2015.

[14] Ş. Toprak, H. Tanak, M. Macit, N. Dege, and M. Orbay, "Experimental and theoretical studies of bis[(E)-1-((3-chloro-4-methylphenylimino)methyl)naphthalen-2-olate-N,O]copper(II),” J. $\quad$ Mol. Struct., 1174, 184-191, 2018.

[15] Ch. Himasekar1, S. Mustafa, and M. S. Babu, "Synthesis, characterization of mixed Cu(II) Pyridyl Tetrazoles and 1,10-Phenanthroline complexes - DFT and biological activity," Open Chemistry Journal, 6, 1-7, 2019.

[16] R. S. Mulliken, "Electronic population analysis on LCAO-MO molecular wave functions. I.’,J.Chem.Phys., 23(10), 1833-1840, 1955.

[17] R.S.J Mulliken, "Electronic Population Analysis on LCAO-MO MolecularWaveFunctions", Chem. Phys.. 23, 1833-1840, 1955.

[18] W. Yang and R. G. Parr, "Hardness, softness, and the fukui function in the electronic theory of metals and catalysis," Proc. Natl. Acad. Sci., 82, 6723-6726, 1985.

[19] H. S. Nalwa and S. Miyata, Non-linear Optics of Organic Molecules and Polymers. CRC Press, Boca Raton, FL, 611, 1997.

[20] A. Hinchliffe and M. H .J. Soscun, "Ab initio studies of the dipole polarizabilities of conjugated molecules. Part 2. Monocyclic azines,” J. Mol. Struct., 110 (2), 109-120, 1994.

[21] S. Eskikanbur, K. Sayin, M. Kose, H. Zengin, V. McKee, and M. Kurtoglu, "Synthesis of two new azo-azomethines; spectral characterization, crystal structures, computational and fluorescence studies," J. Mol. Struct. 1094, 183-194, 2015.

[22] Z. Demircioğlu, C. C. Ersanl, G. Kaya Kantar, and S. Şaşmaz, “ Spectroscopic, Hirshfeld surface, Xray diffraction methodologies and local \& global chemical activity calculations of 5-(2-methoxy-4(prop-1-en-1-yl)phenoxy)pyrazine-2,3-dicarbonitrile", J. Mol. Struct.,1181, 25-37, 2019.

[23] A. E. Reed and F. Weinhold, "Natural bond orbital analysis of near-Hartree-Fockwaterdimer," $J$. Chem. Phys., 78, 4066-4073, 1983.

[24] A. E. Reed and F. Weinhold, "Natural localized molecular orbitals," J. Chem. Phys,. 83, 1736-1740, 1985.

[25] T. Samanta, L. Dey, J. Dinda, S.K. Chattopadhyay, and S.K. Seth, "Structural characterization and Hirshfeld surface analysis of a Co ${ }^{\mathrm{II}}$ complexwithimidazo[1,2-a]pyridine," J. Mol. Struct., 1068, 58-70, 2014. 